\title{
The Perception of Green Promotion and Green Product: A Revolution on Consumer Buying Method
}

\section{Krishanveer Singh ${ }^{\mathrm{a}}$}

${ }^{a}$ Assistant Professor, GLA University, Mathura, India. E-mail: krishanveer.singh@gla.ac.in

Article History: Received: 11 January 2021; Accepted: 27 February 2021; Published online: 5 April 2021

\begin{abstract}
As the natural issues are deteriorating, the purchasers' pursuits approximately the ecological protection have added approximately the broadening in consumer shopping approach in the direction of a green way of existence. Along these strains, companies are making a flow into to make viable organic methodologies within the inexperienced marketplace enterprise. Green showcasing and green item development are valuable techniques which is probably utilized by using agencies to increment top hands and function an opportunity of studying the success of shoppers so on accomplish the affiliation's important imaginative and prescient. Green showcasing and green item improvement have specific blessings to companies regarding developing the maintainable herbal benefits and to create the familiarity with brand photograph of the business employer organization. This exam centers spherical the concept of inexperienced advertising and advertising and inexperienced object development, the particular consumer utilization close to green promoting and inexperienced item improvement, and eventually appears at the troubles that businesses have faced after they have unnoticed to execute inexperienced showcasing and green item development.
\end{abstract}

Keywords: Green Advertising, Inexperienced Object Development, Utilization, Ecological Benefits.

\section{Green Promotion}

Different manufacturers have given special importance to green development. As pointed out in Chaudhary, Trathiathi, and Tonga (2011) the term "publicity that has never been taken and promoted and promoted" was first revealed within the last 1970s. The American Marketing Association (AMA) has described it as a "nature show". The green press includes a large business scale to try real computer games that hope to meet the needs of customers, at the same time as reducing negative effects in the traditional environment (Tiwari, Tripathi, Srivastava, and Yadav, 2011). Green green equally refers to a coalition that places its cohesive components in the development, testing, and mobilization of an existing gadget with concerns about eco-Sarkar, 2012). The American Marketing Association (AMA) has pointed out that the method used to demonstrate that the sale of targeted products is generally a biological circle; the ropes work hard with exercises that include packing exchanges, delivery method, and unrestricted distribution (Yazdanifard and Mercy, 2011). The transparent green and transparent display and advertising and advertising are increasingly portrayed as certain developments that reflect environmental ethics such as the needs of the business office and may be seen as a good opportunity to transform customer leads within the product (Peattie and Charter, 2003). More importantly, the primary objectives of green advertising and advertising were to reduce common risks that could be a direct result of chemical inventions and to support the image of the business community within the customer mindset.

\section{Green Product Development}

The dramatic upgrade of the green object has received much work within the unchanging display design. It can support organizations and the economy floating quickly towards a more balanced balance. The development of the green article underscores the "pipeline development damage" in which organizations perceive growing local issues through machine presentation and object design (Chen, 1994). In particular, Chen (2001) found that this object was intended to combine the use of unlimited resources, to hold the right path from hazardous materials, and the unsustainable source of space for the entire cycle of its existence is likely to be very grateful to show green machines new developments. Most organizations have analyzed the legalization of older home proposals and proposals, for example, Registration, Inspection and Building Materials Limits into a tool for unauthorized improvement; as a result, it can lower the risk of risk in the region at the same time as it diverts customers' appetite for green consumption (Tsai, Chuang, Chao, and Chin, 2012). Green material development includes sewerage, installation, and cost; it will affect consumer purchasing of raw materials (Bing, Chaipoopirutana, and Combs, 2011). 


\section{Consumer Purchasing Approach}

Consumer guidance is indicated by the fact that gaming games for customers who recognize the phone or need it, check records, search, use, and lodge complaints to courses and organizations to satisfy their objectives (Vyas, 2009). By the twentieth century, so many markets were clearly showing real leadership, extravagance, and demanding a customer-buying strategy through that practice within-sales sales. due to the negative effects of the traditional environment, the crippling green demonstration in sports gymnastics is a well-known tool that works for the legacy of a few organizations, and those events found a course in customer targeting strategy within unauthorized gadgets (Cohen, 1973). As a result, the majority of consumers have converted to the belief of "unemployed customers" who were aware of the importance of protecting and securing traditional residence and even searching for eco-bound devices as their enthusiasm for green use grows (Peattie, 2001). Continuing with the triumphs, Boztepe (2012) emphasizes that green clients can stop any food waste or destructive substances that can affect their prosperity, including animal abuse and harm the world in the long run of approach, expulsion or exploitation. Sponsorship support can similarly be planned to enhance customers' reputation for environmental issues with important assets to use exhibitions to get them imported for social reasons urging consumers to move away from cultural objects to issues that force eco-Glyinganda, 2013).

\section{Returns of Green Promotion and Green Expansion}

While organizations use unauthorized use to promote and disclose and promote and advertise within business transformation changes and do things that are not permitted to improve the article, it can reduce recreational activity and creative costs in the day forest. There are organizations that have outsourced the development of a solar-powered career board to their business transformation; it would be equally good to speculate on your favorite savings points (Ottman, Stafford, and Hartman, 2006). Organizations are accustomed to developing an unreachable article to measure object change and contribute to unspecified factors in older domestic problems, including personal hardship, decay of negative social effects and status (Tsai, Chuang, Chao, and Chang, 2012). Also, the organization can edit the structure of the article; can reduce the recognition of the texture to be discarded and plan to choose if it will be obviously dangerous. in the near future, it may be decided in the same way whether or not it can, at present, reduce the use of material resources to promote recycling and recycling (Polonsky, 1994). As shown through Ankit and Mayur (2013), too many sponsors use green promotion with free fraudulent messages to target customers; can improve their perceptions in academics and environmental issues. Without a doubt, organizations can accumulate a picture of their organizations run by the organization and create a customer perspective within the business partnership organization. Significantly, organizations brought in money and promoted individual priorities in the primary markets; it can build up the hands of the organization to achieve a sustainable meeting environment. In addition, delegates may have further development and satisfaction with the stable nature of the business company, thus business performance will be enhanced (Pierce, Rubenfeld, and Morgan, 1991).

Finally, the final delay, the first open source intervention mechanism for organizations that may use the green to indicate that circles can receive grants and FICO points from control to plan the progression of new development (Ottman, 2011). One could hardly say that organizations would consider the risk of globalization favorable and that they would lease commodity-related assets to make use of labor force and progress to achieve productive output and at the same time to perform actual normal operations.

\section{The Relationship among Green Promotion and Consumer Purchasing Behavior}

The displaying combo incorporates object, charge, advancement, and spot (4P's). The parts of exhibiting total in unpracticed publicizing and promoting are significant for sponsors to apply to achieve the connection's objectives. As showed through Young, Hwang, McDonald, and Oates (2010), there are 30\% of customers communicated that green devices should be power viable, direct in water safeguarding, be covered with respect to the field in some unknown time inside the predetermination of the methodology of creation, use and evacuation. The insecure substance of an article may also affect the clients' searching for decisions; because of this the makers will normally create the issues which can be eco-obliging to fulfill the enthusiasm of unpracticed customers. There are universal organizations that use green promoting to made $1 / 2$ variety vehicles that purposefully hope to direct the diversion of the undertaking office's salaries with the association' obligation to decrease the natural consequences of contamination. For example, Toyota produces Prius which offers numerous charming points of interest for customers and therefore the indigenous natural surroundings (Halbright and Dunn, 2010). Prius capabilities a characteristic engine which joins spread reducing fuel, so it might decrease the release of $\mathrm{CO} 2$ and dioxide in to the atmosphere; lower surges will achieve to a momentous effect at the part, cutting down the pollution created in to the environmental factors. On the off threat that adequate people have 
been to get a Prius, it may be fought that it'd largy affect a worldwide temperature change, anyway the proposal of 1 of those autos won't post of the issue (May, Cheney, and Roper, 2007). on account of the charge of gas extending, Toyota brought Prius which would perhaps at the same time moreover save rate in gas, which can be a wonderful factor if various buyer's emotions. Buyers who've durable characteristic worries, for example, agonizing around the common occasions and assurance to the field, will conceivably reason naturally insightful searching for and use of a portion of and half of vehicle (Balderjahn, 1988). One likewise can say that Prius fulfill the interest of the clients for an eco-obliging article. As an extreme outcomes, the clients imparted super accomplishment toward the eco-obliging thing; it builds up an uncommon judgment inside the course of Toyota Corporation and thusly the customers had been perhaps to trust in the unflinching surprising of the Toyota's devices. Next, the expense of an article wishes to be vacillated to the individual compensation of the client. A curiously large piece of the organizations is the use of low-value strategies to start off the customers to get ecoobliging gadgets. over the span of this condition, the enterprises make a whip hand inside the modern center so on development the association improvement. On the off danger that the pace of an article is better; the organizations were given to part the estimation of the prevalent thing inside the data helpful, detail and appearance (Chandra, 2009). Starbucks can be a universal enterprise that is advancing at a more significant expense than consistently and ethically property its devices which shows they're centered around being earth careful, while banishing the natural impressions by lessening texture waste and building green and power capable shops ("Global", 2014). Likewise, Coffee and Farmer Equity (C.A.F.E) Practices conceded Starbucks' coffee; the confirmation of coffees the clients' objectives, however moreover empowers improving inside the assurance of condition ("Global", 2014). The customers who're of a low-charge affectability are fulfilled to pay more on the thing than the assortment of rate, besides observe that the estimation of the eco-obliging thing an incredible equivalent old expense for an item inside the enormous terms of expense and marvelous (Eze and Ndubisi, 2013). Along the one's lines, the customers who are looking for to pay top excellence for Starbucks' gadgets in slight of the very reality that the unpracticed brand charge of Starbucks is responding to ecological exchange and being proactive in its aura toward disease inconveniences. Furthermore, the clients one of a kind generously inside the course of the green gadgets and this may carry a useful absolute last outcome to the symbol cost and augmentation the risk of purchases a short time later (Chen, 2010). Green publicizing might be a limited time strategy which allows in the sponsors to use novel and imaginative strategies to upgrade the article. The vigorous convincing message from the unpracticed ads makes the customers notoriety at the difficulties being revealed to them, on the equivalent time as impact customers' purchase lead close to the business partnership organization's image (Zinkhan and Carlson, 1995). Sharma (2011) concluded that there are 3 proportions of unpracticed know which is presumably the consideration begins developed off cutting edge with educational substance that stress for the territory, the mindfulness communicates the organizations have altered the strategies of creation so on progresses an unpracticed way of life and therefore the consideration has an unscrupulous to an affiliation's photograph of regular obligation. As ordinary with Laric and Lynagh (2010) communicated that Samsung have a characteristic programming application named as "Planet First" which altered into intentionally familiar with balance the interest for driving component development with the duty of bringing down the natural impacts so on upgrade a green way of life. besides, Samsung passed on their obligation of green duty and unpracticed messages to the customers by means of the Samsung web net page and ESPN Magazine, subsequently it can development the business enterprise's commitment to reasonability (Laric and Lynagh, 2010). Sooner or later of this situation, the clients structure sentiments when provided to green modern association which influences their air and acumen inside the course of the unpracticed advertisement and feelings roughly the company photograph (Cox, 2008). What's extra, the normal occasions from the advertisement will lead the customers to keep on inside the bearing of a stupendous ecological way and it'll impact their purchase desire for that thing. At extensive shutting, the organizations were given to offer the thing at a key recognize that is surprising for shoppers to achieve to so it'd impact the buy want of clients. Most promoters practically positioned new green contraptions inside the partnership place as long as a result of reality the area was more noteworthy wonderful than that of a business organization undertaking from its opponents. For instance, Starbucks produces the unpracticed idea in its stores all round so on envelop the method of diminishing the characteristic risk to shape the legitimacy of the office ("Global", 2014). The catchphrase of "Spot" in promoting and showcasing and showcasing and publicizing and promoting and publicizing and promoting and advertising mix also implies substantially appointment which can be a mess of big business partnership real computer games that has the event of setting ceaselessly and delivering finished contraptions at the equivalent time as meaning to live up stress with the natural commitment of the company.

For instance, reducing the thickness of packaging can diminish the gas that is wolfed by way of vehicles and it could diminish the negative results in the city. B\&G focused on the "brought together scattering" programming program programming and subsequently the dream of methods that flexibly natural points of interest, for example, reducing the repeat the measure of vehicle inclinations on the indistinguishable time as the reduction in gas use which cuts down the difficulty of defilement, therefore the association has been conceded with 
environmental enormity (Peattie and Charter, 2003). Mohr, Webb, and Harris (2001) mounted that there are trial researches that have demonstrated that unreasonable business undertaking social obligation levels of the organization association determinedly sway the customers' buying for decision.

\section{The Connection between Green Expansion and Consumer Buying Actions}

Regarding the song with Parry (1997) there are eight possible ways to improve; a vision of time and testing, an opportunity assessment of the office of the local president, special use, observation and marketing materials. Similarly, green development includes eight areas of development and toxicity testing that can be processes of understanding environmental hazards, gaining awareness of the benefits of a few unknown periods of pollution within the end of the commercial life cycle and reducing the natural limit of potential outcomes (Bhat, 1993). It is guaranteed that customers have purchased in the most difficult environment, and this should be incorporated into non-existent items to be considered satisfactory in their key markets. Consumers who are concerned about the natural effect of a product are more likely to get raw materials when they will be needed; in addition they are more likely to pay a higher price for such items in the event that they are perceived as better in the environment (Laroche, Bergeron, and Barbaro-Forleo, 2001). One of the most important variables for green improvement is the announcement and promotion of eco-item marks on items. Eco branding is a state-of-the-art technology that can also provide records with policy capabilities that is a trademark that adheres to the general trend of the intangible and thus cost-effectiveness that gives the business office a business image of the business entity (Sammer and Wustenhagen, 2006). within the eyes of customers, the eco-mark is a development. This true content is given with honesty and therefore the names that provide the orders used and expected by the customers, because they depend on the basic values that consumers want the information they choose (Pedersen and Neergaard, 2006). Rashid (2009) pointed out that environmentally friendly consumers are licensed to classify products that may be the most significant in the market, as the call all term results began to show environmental sales. Also, the eco name of the sale makes a good impression on the client's understanding and as a result the product's web page works for consumers who want to buy it first (Purohit, 2012). Much of the eco-Nordic Swan examples of energy conservation and conservation, these environmentally reliable records determine the impact consumers are buying within the logo logo and will enhance the number of organizational benefits (Bjorner, Hansen, and Russell, 2004).

\section{Difficulties While Going Green}

There are offices that use green gestures and promotions to protect their work and are strong and prudent, yet there are many corporate sites that neglect to contribute to transparent green displays of self-awareness and appreciation and visual representation, where business people did not practice illegal promotion. In this way, circles need to follow legal rules and guidelines that adhere to the guidelines that do not mislead any clients or individuals working independently (Chowdhury and Dasani, 2013). Companies need to fill in proposals that reflect the interests of nature, provide natural approaches, clarify how natural resources are made, create equitable gifts, prevent the creation of hazardous substances and transfer natural cases to an image or text (Polonsky, 1994). part of the organizations has new clinical and peer performance information, which makes it clear that many negative co-operative decisions have to be made that do not mean what is most threatening among environmental factors. For example, a few circles have used DME as an air force; will increase the negative impact on the ozonosphere (Fleisch, Basu, Gradassi, and Masin, 1997). Most of the customers at the time were unaware of the serious environmental issues that had arisen to affect the use of the product. Since this episode it is assumed that customers will not focus on natural conditions from the green office for another product (Golkonda, 2013). Chan (2004) found that the declaration of natural ecosystems from the green business that should not figuratively represent the eco-driven image, as a result of which the advertised object ignores drawing customer perceptions. In the results, clients found that the general trend in the performance of nonconsumer products made with recycling materials or a recycled store made it more common to make more with a traditional product and subsequently consumers are less likely to search for a higher value item (Michaud and Llerena, 2011). the path to true customer demand, clients will not be as secure as reality in eco-names; will close within customers looking for eco placement (Cherian and Jacob, 2012).

\section{Argument}

The examination of this paper plan to check how green showcasing and publicizing and advertising and unpracticed improvement and the way it impacts the shopping approach of clients. This exploration paper is basic because of the reality the region is presently confronted with ecological destruction and poisons levels have end up being more regrettable day by means of day, that could eventually reason the continuous weakening of human presence. Green promoting and showcasing and publicizing and showcasing and promoting and 
advertising may furthermore be a way that tends to the worry of selling and protecting the common habitat which would likely also pick up the organizations, clients and environmental factors at the indistinguishable time as the unpracticed item is progressed. Most associations have started out to work out the idea of green publicizing and promoting and green improvement inside the everyday association activities to gracefully eco-accommodating items that permits you to satisfy the customer's fantasies and wishes. Past this present, there's a move in customer's conduct toward a greener way of life; it's known as the green client. While the organization business association satisfies the decision for of buyers, it welcomed on the gathering of the business venture to extend. The eco-driven photograph of the organization enterprise causes a significant to effect of in customer's discernment; subsequently, the company can get the great pride and gather as real with from clients without any problem. In outcomes, the association which carries on in a naturally capable manner is likely going to perceive extensive time span benefit and ecological maintainability. As the ecological difficulties have intensified, most extreme worldwide organizations have started to utilize the promoting and showcasing blend thought in unpracticed advertising that can likewise moreover accumulate the association task and vision in brief periods. The offices need to select the customers natural needs and create green product which surpass the regular old anticipations of customers. In addition, associations need to ensure that the in truth well worth of the green item on the problem of ordinary execution, structure, and obvious intrigue ought to surpass the definitely genuinely well extremely worth of the green item. Most organizations utilized green boss as a limited time technique which also can furthermore show clients the method of defensive the earth and it might in addition set up the eco-driven photo of the organization. Furthermore, the circumstance of the shops needs to be to be had for the clients to get to. The organizations need to diminish the natural results on the equivalent time as dishing out and shipping the crude materials or completed products. Eco-marks were an exceptionally critical issue inside green turn of events, it much of the time presents customers with a reliable sign of an items social and natural certifications. The additional customers slanted to purchase a green item, the additional associations are sorted out to test the adjustments in dreams and direct of the clients. Nonetheless, there are organizations that put into sway green promoting and unpracticed item tendencies improperly and it results inside the commonness of difficulties with the goal that you can trouble the endeavor inside the fate. For example, the low seen believability of natural cases in green undertaking can additionally reason the clients to have terrible mentality in the way of the business after they go to buy an equivalent item internal the future on the off chance that they're not prevented essentially inside the principal occurrence. Accordingly, the advertisers need to frame their unpracticed publicizing and showcasing and promoting approach with care and exactness ahead of time than they situated into impact the merchandise in to their venture. The rationale of key arranging can protect client's maintenance; furthermore, as limiting ecological impacts as a way to comprehend predetermination productivity and blast.

\section{Supposition}

As the creating inconvenience of natural issues had headed out to make, society and consequently the specialists have begun to experience in considerations about the ones issues and start to frame changes to envelop the horrible aftereffects of these difficulties. Green publicizing and promoting and stock advancement are esteemed the best procedures previously for a business manager association to be set up to adjust with new decisions from the govt, and additionally to be sorted out to fits the conduct of clients from field concentrates in to the prerequisites and wishes. The organizations accepted that the contemplations of green publicizing and showcasing like authorizing an unpracticed convey chain, unpracticed items configuration, bundling, estimating and elevating are advantageous to society and hence the earth; and in this manner, it's outweighed ordinary promoting and publicizing and advertising activities. Moreover, the organizations need to give first rate endeavors to its clients toward the finish of a way that shows the office is effectively scanning for to diminish its environmental factors peril. Last, executing green promoting and showcasing and green improvement approach aren't tangled, anyway as an option a relative thought that consistently varies over the time

\section{References}

1. Boztepe, A. (2012). Green promotion and its impact on consumer buying behavior. European Journal of Economic and Political Studies, 5(1).

2. Chen, Y. (2010). The drivers of green brand equity: Green brand image, green satisfaction, and green trust. Journal of Business Ethics, 93(2), 307-319. http://dx.doi.org/10.1007/s10551-009-0223-9

3. Cherian, J., \& Jacob, J. (2012). Green promotion: A study of consumers' attitude towards environment friendly products. Asian Social Science, 8(12). https://doi.org/10.5539/ass.v8n12p117

4. Chowdhury, S., \& Dasani, L. (2013). Green promotion- A new corporate social responsibility. ASM's International E-Journal of Ongoing Research in Management and IT.

5. Eze, U.C., \& Ndubisi, N.O. (2013). Green buyer behavior: Evidence from Asia Consumers. Journal of 
Asian and African Studies, 48(4), 413-426. https://doi.org/10.1177/0021909613493602

6. Laric, M. V., \& Lynagh, P.M. (2010). The role of integrated marketing communications in sustainability marketing. ASBBS Annual Conference: Las Vegas, 17(1).

7. Michaud, C., \& Llerena, D. (2011). Green consumer behavior: an experimental analysis of willingness to pay for remanufactured products. Business Strategy \& the Environment, 20(6), 408-420. https://doi.org/10.1002/bse.703

8. Ottman, J.A. (2011). The new rules of green promotion: Strategies, Tools, and Inspiration for Sustainable Branding. http://www.greenleaf-publishing.com/content/pdfs/NRoGM_ch1_2.pdf

9. Purohit, H.C. (2012). Product positioning and consumer attitude towards eco-friendly labeling and advertisement: An analytical study. Journal of Management Research, 12(3), 153-162.

10. Sarkar, A.N. (2012). Green branding and eco-innovations for evolving a sustainable green promotion strategy. Asia-Pacific Journal of Management Research and Innovation, 8(1), 39-58. https://doi.org/10.1177/2319510X1200800106

11. Tiwari, S., Tripathi, D. M., Srivastava, U., \& Yadav, P. K. (2011). Green promotion - emerging dimensions. Journal of Business Excellence, 2(1), 18-23.

12. Tsai, M.T., Chuang, L.M., Chao, S.T., \& Chang, H.P. (2012). The effects assessment of firm environmental strategy and customer environmental conscious on green product development. Environ Monit Assess, 184, 4435-4447. https://doi.org/10.1007/s10661-011-2275-4

13. Young, W., Hwang, K., McDonald, S., \& Oates, C.J. (2010). Sustainable consumption: Green consumer behavior when purchasing products. Sustainable development, 18, 20-10. https://doi.org/10.1002/sd.394 